OPEN ACCESS

Edited by:

Takashi MaruYama,

National Institutes of Health (NIH),

United States

Reviewed by:

Danqing $\mathrm{He}$

Peking University Hospital of

Stomatology, China

Carla Alvarez Rivas,

The Forsyth Institute, United States

Yang Li,

Affiliated Stomatology Hospital of

Guangzhou Medical University, China

*Correspondence:

Chider Chen

chenc10@upenn.edu

Specialty section:

This article was submitted to

T Cell Biology,

a section of the journal

Frontiers in Immunology

Received: 02 December 2021

Accepted: 20 January 2022

Published: 10 February 2022

Citation:

Jiang Q, Huang X, Yu W, Huang $R$,

Zhao $X$ and Chen $C$ (2022) mTOR Signaling in the Regulation of CD4+ $T$ Cell Subsets in Periodontal Diseases.

Front. Immunol. 13:827461.

doi: 10.3389/fimmu.2022.827461

\section{mTOR Signaling in the Regulation of CD4+ T Cell Subsets in Periodontal Diseases}

\author{
Qian Jiang ${ }^{1}$, Xiaobin Huang ${ }^{1}$, Wenjing $\mathrm{Yu}^{2}$, Ranran Huang ${ }^{1}$, Xuefeng Zhao ${ }^{2,3}$ \\ and Chider Chen ${ }^{1,4 *}$ \\ 1 Department of Oral and Maxillofacial Surgery and Pharmacology, School of Dental Medicine, University of Pennsylvania, \\ Philadelphia, PA, United States, ${ }^{2}$ Department of Orthodontics, School of Dental Medicine, University of Pennsylvania, \\ Philadelphia, PA, United States, ${ }^{3}$ State Key Laboratory of Oral Diseases, National Clinical Research Center for Oral Diseases, \\ West China Hospital of Stomatology, Sichuan University, Chengdu, China, ${ }^{4}$ Center of Innovation and Precision Dentistry, School \\ of Dental Medicine, School of Engineering and Applied Sciences, University of Pennsylvania, Philadelphia, PA, United States
}

Periodontal disease results from the inflammatory infiltration by the microbial community which is marked through tooth mobility and alveolar bone resorption. The inflammation in periodontal disease is mediated by $\mathrm{CD}^{+} \mathrm{T}$ cells through cytokine secretion and osteoclastogenetic activity. Historically, the inflammatory model in periodontal disease is described through disruption of the balance between two subsets of Thelper cells which are T-helper type 1 (Th1) and T-helper type 2 (Th2). However, more and more studies have found that apart from subsets of helper T cells, regulatory T-cells and Th17 cells are also involved in the pathogenesis of periodontal diseases. Growing evidence proves that helper $\mathrm{T}$ cells differentiation, activation, and subset determination are under the strong impact of mTOR signaling. mTOR signaling could promote Th1 and Th17 cell differentiation and inhibit Treg commitment through different mTOR complexes, therefore we anticipate a regulation effect of $\mathrm{mTOR}$ signaling on periodontal diseases by regulating $\mathrm{CD}^{+} \mathrm{T}$ cell subsets. This review aims to integrate the topical researches about the role of different types of Th cells in the pathogenesis of periodontal diseases, as well as the regulation of mTOR signaling in the specification and selection of Th cell commitment.

Keywords: periodontal disease, inflammatory, $\mathrm{CD}^{+} \mathrm{T}$ cells, immune response, $\mathrm{mTOR}$ signaling

\section{INTRODUCTION}

A new periodontitis classification scheme has been adopted by the World Workshop in 2018, in which three forms of periodontitis can be identified: necrotizing periodontitis, periodontitis as a manifestation of systemic disease, and the disease previously recognized as "chronic" or "aggressive" are now grouped under a single category, "periodontitis" and are further classified based on a multidimensional staging and grading system $(1,2)$. Periodontitis is an inflammatory disease that damages the soft tissue and, without treatment, can result in progressive destruction of the periodontal ligament and alveolar bone with periodontal pocket formation, gingival recession, and even tooth loss (3). Periodontal disease does not only affect the gums tissue but also has been 
stated to be a potential risk factor for systemic diseases such as cardiovascular disorders, low birth weight infants, and several others due to exposure of bacteria from periodontal tissue to blood and the resultant production of inflammatory mediators (4-6). The periodontal disease has been better understood through the latest findings in the field of microbiology and immunology. Recent researches in microbiology have shed better light on the mechanism behind the development of periodontitis (7), whereas immunobiology studies have revealed that periodontitis is caused by immune responses against bacterial infection which eventually results in periodontal tissue damage (8). It has been established that the immune responses of the human immune system determine the susceptibility to periodontitis. However, the exact role of different subsets of immune cells in periodontitis, the role of immunity in alveolar bone destruction, and the specific signaling pathways involved in immune regulation in periodontitis remain unclear.

Periodontitis is the inflammatory process with a dense accumulation of immune cells, including neutrophils, macrophages, lymphocytes, plasma cells, and mast cells (9). The lesion is initiated by the response of resident leukocytes and endothelial cells to the bacteria, which produce cytokines and cause vasodilatation of local blood vessels. Neutrophils migrate out of blood vessels into the site of infection in response to chemokines. The numbers of neutrophils increase and macrophages, lymphocytes, plasma cells, and mast cells also appear in the connective tissue. The following stage is the established lesion, which is the period of transition from the innate immune response to the acquired immune response. At this stage, plasma cells, macrophages, and T and B lymphocytes are dominant. The final stage is the advanced lesion, which is characterized by irreversible attachment loss and bone loss (10). $\mathrm{T}$ cells play an important role in this process of the immune response, regulating the polyclonal activation of the B cells (11), inducing osteoclastogenesis via RANKL activation, and producing several periodontitis-associated cytokines, such as IFN- $\gamma$, TNF- $\alpha$, and interleukin (IL)-17 $(12,13)$.

It has been reported that human $\mathrm{CD}^{+} \mathrm{T}$ cells are involved in the immune response against oral microorganisms in periodontal diseases (14). In general, $\mathrm{CD} 4^{+} \mathrm{T}$ cells with regulatory function play a crucial role in controlling the immune responses during host defense (15). Different subsets of $\mathrm{CD}^{+} \mathrm{T}$ play role in the chronic inflammatory conditions distinctively (16), however, their exact contribution towards the destruction of the periodontal tissue destruction has not been understood. Although the pathological studies in periodontitis have made a significant advancement, the overall understanding of the role of immunity in the pathogenesis of periodontal diseases is still limited. The understanding of the exact role of immune cells in periodontitis is crucial for discovering novel treatment strategies.

In this review, we have summarized the latest researches describing the role of different subsets of $\mathrm{CD}^{+} \mathrm{T}$ which include helper T cells type 1 (Th1), Th2, Th17, and regulatory $\mathrm{T}$ (Treg) cells in the induction of immune response in chronic periodontal diseases. Moreover, we focused on the $\mathrm{CD}^{+} \mathrm{T}$ regulation by mTOR signaling, which is known to control cell differentiation, activation, and fate determination in $\mathrm{CD}^{+} \mathrm{T}$ cells. $\mathrm{T}$ cell activation is accompanied by a wide variety of changes in cellular metabolism and is guided by multiple cues derived from the immune microenvironment (17). The mTOR cascade is the central integrator of these signals and has an essential role in driving $\mathrm{T}$ cell differentiation and function $(17,18)$. This way mTOR pathway impacts the selection and fate of $\mathrm{CD} 4^{+} \mathrm{T}$ cells which ratify their role in the pathology of periodontal diseases. This study not only elucidates the relationship between immunity and periodontal diseases but also highlights the potential directions towards the development of novel therapeutic approaches.

\section{PATHOBIOLOGY OF PERIODONTAL DISEASES}

Periodontitis is characterized by the inflammation caused by microorganisms in periodontal soft tissues and the gradual loss of periodontal alveolar bone (19). The progressive destruction of periodontal tissues results in tooth looseness and eventually loss of teeth resulting in tremendous social and economic burden for patients $(20,21)$. Periodontitis is reported to be one of the most prevalent chronic inflammatory condition which affects more than 700 million people worldwide (21).

Historically, it was believed that periodontitis is caused by specific bacterial infections and that people are unanimously susceptible to these infections and to the damage caused by them (13). Chronic inflammatory periodontal diseases are induced by imbalanced microbial communities which are presented in the form of subgingival dental plaques. Dental plaque is a typical biofilm composed of complex microbial flora (22), and the microbes in the plaque are highly ordered and embedded in an extracellular matrix. Subgingival biofilms are dental plaques that locate at the root surface of teeth or dental implants, in which the external surfaces are exposed to the gingival tissues. The transition from healthy periodontium to inflammatory periodontium is not implicated by a single type of organism. The microbial communities in periodontal diseases exhibit dysbiosis with unregulated microbial species composition and abundance, which results in a pathogenic condition (23). Three Gram-negative organisms, Prophyromonas gingivalis, Treponema denticola, and Tannerella forsythia, identified as "Red Complex", were the first organism found to be associated with periodontal disease with their enriched presence in subgingival plaques within the periodontitis patients (24). Although these microorganisms are linked with the pathological condition, they are also normally present at a low level in healthy patients without periodontal diseases, suggesting that they are pathobionts rather than pathogens. Other microorganisms in periodontal tissues which are also found to be pathobionts include Parvimonas, Fusobacterium, and Prevotella (25). 
Nowadays, it has been accepted that the pathogenesis of periodontitis is more complex than the presence of virulent microorganisms (13). The microbes associated with periodontitis progressively destroy the periodontal tissues by producing numerous detrimental cytokines and virulence factors including exotoxins, endotoxins, fimbriae, capsule, and metabolic products (26). However, not all individuals with periodontitis-associated microbes in their gum tissues develop periodontitis, indicating a complex multifactorial etiology associated with periodontal diseases. In addition, there are intractable cases that responded poorly to the comprehensive periodontal treatment suggesting a disease susceptibility model (27). At present, it has become apparent that, except for the microorganisms, the modifiable risk factors (eg. smoking) and non-modifiable risk factors (eg. genetic inheritance and immune response) are critical etiologic agents in periodontal disease (13).

Smoking negatively affects periodontal health, which has been proved by epidemiological, clinical and in vitro studies (28-31). Compared with nonsmokers, smokers have presented increased susceptibility, greater severity, and faster progression of periodontitis $(32,33)$. Besides, smokers lose more teeth and are less likely to be successful in periodontal treatment than nonsmokers (33). It is reported that smoking reduces gingival bleeding by reducing the number of gingival blood vessels or altering the caliber of the blood vessels perfusing the gingival tissues (34). The decreased bleeding indicates an underlying disruption of the immune response, which may lead to the increased loss of attachment and alveolar bone $(34,35)$. More importantly, smoking cessation seems to be favorable for the periodontium, which decreases the risk for the incidence and progression of periodontitis $(36,37)$.

Another new discovered etiologic agent in periodontal disease is genetic inheritance. A recent meta-analysis concluded that up to a third of cases of periodontal diseases are due to the involvement of causative genetic factors and severe periodontitis shows higher heritability than moderate periodontitis (38). The specific genes which are responsible for periodontitis are not identified yet whereas the heritability of periodontitis has been found to be regulated by epigenetic mechanisms $(26,39)$. The heritability considered to be a relative contribution to periodontitis denotes that certain other factors might be increasing the risk, implying that the relative contribution of genetics would be moderate (38).

Many studies have reported the associations between periodontal diseases and immunocompromised systemic diseases, such as diabetes mellitus and rheumatoid arthritis (40-43). It has been generally accepted that immune system is pivotal in the etiology of periodontitis and the major cause of periodontal diseases is an imbalance between host immunity and microbial virulence (44). The individual susceptibility of the disease is regulated by the host immunity, which is also affected by environmental factors (45). Exploring the inflammatory conditions in periodontal tissues with their mode of inflammation and tissue destruction holds a pronounced significance. Understanding the regulatory pathways in inflammatory response causing periodontal tissue destruction may pave way towards a new therapeutic avenue.

Inflammation is the physiological response to the injury or the infection. In case an injury persists, the acute immune response transforms into a chronic immune response which is accompanied by the activation of adaptive immune responses. The innate and adaptive immunity must be coordinated to return the injured tissue to homeostasis, including the repair and the regeneration of lost or damaged tissues (45). Knowledge of how immunological mechanisms and inflammatory responses regulation is critical for understanding the pathogenesis of periodontitis (45). The innate immune system constitutes cells of hematopoietic and nonhematopoietic origins, including myeloid cells of hematopoietic origin (phagocytes) and epithelial cells (46). Besides these cells, there is an innate humoral response through the complement cascades. Innate immunity is a non-specific type of immunity characterized by phagocytosis in which macrophages and neutrophils digest microorganisms and foreign substances (47). When infection does not clear off, it leads to the formation of a chronic lesion, stimulating the innate immune response which eventually activates the adaptive immune response. The adaptive immune response is specific to the pathogen presentation. The cells of the adaptive immune response are lymphocytes, including B cells and $\mathrm{T}$ cells which are associated with antibody responses and cell-mediated immune responses, respectively.

In periodontal tissue, the formation of polymicrobial biofilm (plaques) stimulates a local inflammatory and immune reaction (Figure 1A). Currently, pathogen-associated molecular patterns (PAMPs) derived from pathogens and damage-associated molecular patterns (DAMPs) released from damaged or necrotic host cells have been considered to be crucial for inducing innate immune responses in bacterial infection (48). The recognition of PAMPs and DAMPs by host cells initiates innate immune response through toll-like receptors (TLRs) (49, 50). TLRs present on periodontal epithelial cells and immune cells can recognize highly conserved structures of bacteria, such as lipopolysaccharide (LPS), peptidoglycan, and double-stranded RNAs (51). LPS and other plaque PAMPs as well as DAMPs activate the high endothelial venules (HEVs) in the gingival lamina propria $(52,53)$ (Figure 1B). The injection of LPS from various microorganisms into the gingival tissues established periodontitis model characterized by increased infiltration of leukocytes, higher levels of proinflammatory cytokines, collagen degradation and alveolar bone resorption (54). LPS-activated endothelial cells (ECs) disrupted EC barrier leading to vascular hyperpermeability, leakage of albumin and polymorphonuclear $(\mathrm{PMN})$ transmigration $(55,56)$. When PMNs transmigrate across the HEVs, they will be further attracted to the crevice by PAMPs and DAMPs. Enhanced accumulation of PMNs is associated with the increase of interleukin-8 (IL-8), intercellular adhesion molecule 1 (ICAM1), IL-1 $\beta$, and tumor necrosis factor$\alpha$ (TNF- $\alpha$ ) expression level (57), which maintain EC activation. The vicious circle of PMN/HEV mutual activation may cause an exaggerated PMN response and a damage to the periodontal 
tissues (58). Therefore, the innate immune response is characterized by a dense inflammatory infiltration in the periodontal tissues, in which PMNs and macrophages are abundant immune cells.

When inflammation is persistent, macrophages can act as professional antigen-presenting cells (APCs), and stimulate $\mathrm{CD}^{+}$helper $\mathrm{T}$ cell responses (59). PMN can also be activated to function as accessory cells for $\mathrm{T}$ cell activation (60). APCs interact with naive $\mathrm{T}$ helper cells (Th0), driving their differentiation into several subsets, including Th cells and Treg cells (61) (Figure 1C). Activated lymphocytes initiate adaptive immunity and secrete proinflammatory cytokines and chemokines (62). The intensification of the local immune response leads to the expansion of inflammation and results in the progression of periodontal destruction including alveolar bone loss (63) (Figure 1D). Besides, memory T cells are crucial part of the immune surveillance in periodontium and important for maintaining periodontal homeostasis (64). Emphasis has been placed on the $\mathrm{T}$ cell response in controlling local immunity and causing chronic periodontal tissue destruction, however, minimal memory $\mathrm{B}$ cells also reside in the connective tissue of clinically healthy gingiva (65). The low levels of memory $\mathrm{B}$ cells in healthy gingiva seem to play an important role in avoiding bone loss caused by the subclinical inflammation (9). Although it is well-recognized that periodontal destruction is caused by the host inflammatory response to bacterial infection,

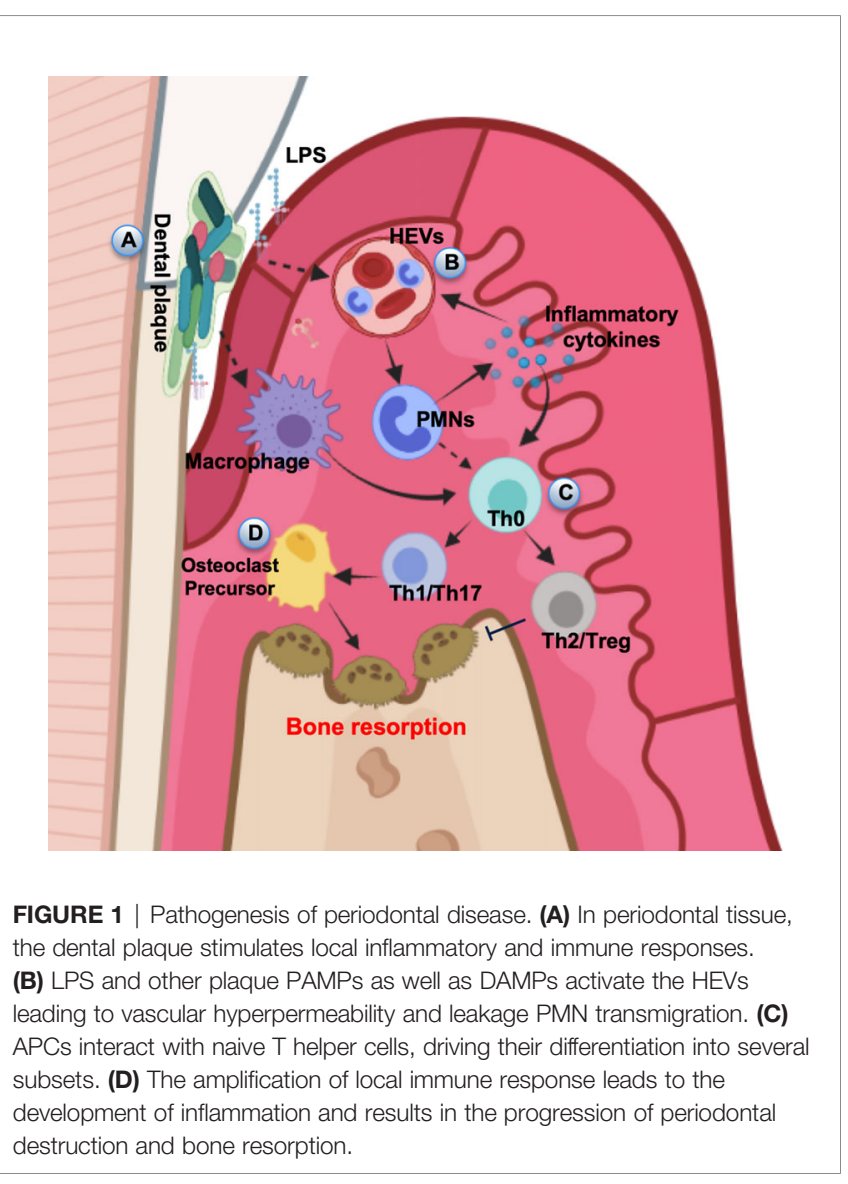

the potential contributions and detailed molecular mechanisms of $\mathrm{T}$ cell differentiation and activation need to be further explored in future studies to develop effective and safe therapeutic approaches.

\section{THE FUNCTION OF CD4 ${ }^{+} \mathrm{T}$ CELLS IN PERIODONTAL DISEASES}

The phenotype of periodontal diseases is characterized by the resorption of alveolar bone and tooth mobility. Adaptive immune responses have a main role in controlling the remodeling of bone $(66,67)$. $\mathrm{CD}^{+} \mathrm{T}$ helper cells which are an important component of the adaptive immune system, regulate the bone resorption process by producing cytokines (68). However, the development of $\mathrm{CD}^{+} \mathrm{T}$ cells is extremely complicated and strictly controlled by multiple signaling. With the stimulation by bacteria or viruses, naïve $\mathrm{CD} 4^{+} \mathrm{T}$ cells could differentiate into various subsets, including Th1, Th2, Th17, and Treg cells. Different subsets show distinctive function during immune response whereas the commitment of a specific subset of $\mathrm{CD}^{+} \mathrm{T}$ cells largely depends on the cytokines produced in the microenvironment. Th1 cells are characterized by the expression of interferon- $\gamma($ IFN- $\gamma$ ) (69), which are considered to mainly fight intracellular pathogens like bacteria or viruses (70). Th2 cells are defined by the expression of IL-4, IL-5, and IL-13 (71), which are perceived to mainly target extracellular parasites like helminths and allergic inflammatory responses (72). Th17 cells are defined by the expression of IL-17 and IL-22, which in responses to extracellular pathogens including bacteria and fungi (73). Treg cells exert their function by regulating immune responses to maintain immune homeostasis and prevent immunopathology (73).

In periodontitis, traditionally, Th1 cells are considered to be connected with the primary and stable periodontal lesions, whereas Th2 cells tend to be linked with progressive periodontal lesions (74). Specifically, a strong innate immune response results in the production of IL-12 by dendritic cells. The naive $\mathrm{T}$ cells activated by IL-12 (75) gain IFN- $\gamma$ producing capacities, which become so-called Th1 cells. The production of IFN- $\gamma$ enhances the phagocytosis of both neutrophils and macrophages and hence restrain the infection (74). However, the stable lesion persists because of the continual stimulation of the dental plaque. The naive T cells can undergo a different fate and become Th2 cells when the innate response is poor and low levels of IL-12 are produced. Th2 cells produce mainly IL-4 and also produce IL-5, IL-10, and IL-13, but not IFN- $\gamma$. The stimulation of mast cells and the production of IL-4 will lead to B cells activation and antibody production. When the antibody is protective, the disease will not deteriorate. When the antibody is non-protective and cannot clear the infection, the infection will persist and the continuous activation of B cells will lead to large amounts of IL-1 and tissue destruction (74). Nevertheless, the conventional theory about Th1 versus Th2 has been proven to be unsatisfactory in the explanation of periodontal diseases since contradictory results were reported (76). In animal models 
of bone disease, IFN- $\gamma$, which is secreted by Th1 cells, promotes osteoclastogenesis and hence bone loss $(77,78)$. However, in vitro experiment, IFN- $\gamma$ is shown to block RANKL signaling and thus inhibit osteoclasts differentiation (79), which proves a negative link between Th1 cells activation and bone resorption. These results represent the debatable role of IFN- $\gamma$ and Th1 in osteoclastogenesis and bone resorption. Besides, some cytokines secreted by Th cells do not fit obviously into either category which means new Th cell subsets should be involved.

The role of Th1 in periodontitis is debatable, but many studies have revealed that Th1 cells are involved in the progression of periodontal diseases, especially induced osteoclastogenesis and alveolar bone loss (Figure 2). IFN- $\gamma$ is the signature cytokine of Th1 cells. Th1 polarization is induced by the IL-12 and IFN- $\alpha$ produced by the dendritic cells or the natural killer (NK) cells in the inflammatory milieu (80). Osteoprotegerin ligand (OPG-L) predominantly expresses in Th1 cells and stimulates osteoclast differentiation leading to bone resorption by the activated osteoclasts (81). The involvement of $\mathrm{T}$ cells in periodontal bone resorption largely depends on the recruitment of Th1 cells into the inflamed periodontal tissues (81). The injection of IFN- $\gamma$ into the mice with periodontitis further enhanced the alveolar bone loss (82). Moreover, Th1 cells are found to provide proosteoclastogenic supports, along with pro-inflammatory cytokines that consequently lead to periodontal lesion progression (83). Interestingly, the interactions between Th cells and osteoclasts represent an intriguing aspect in osteoimmunology research field (84). In the osteoimmunology research, it is reported

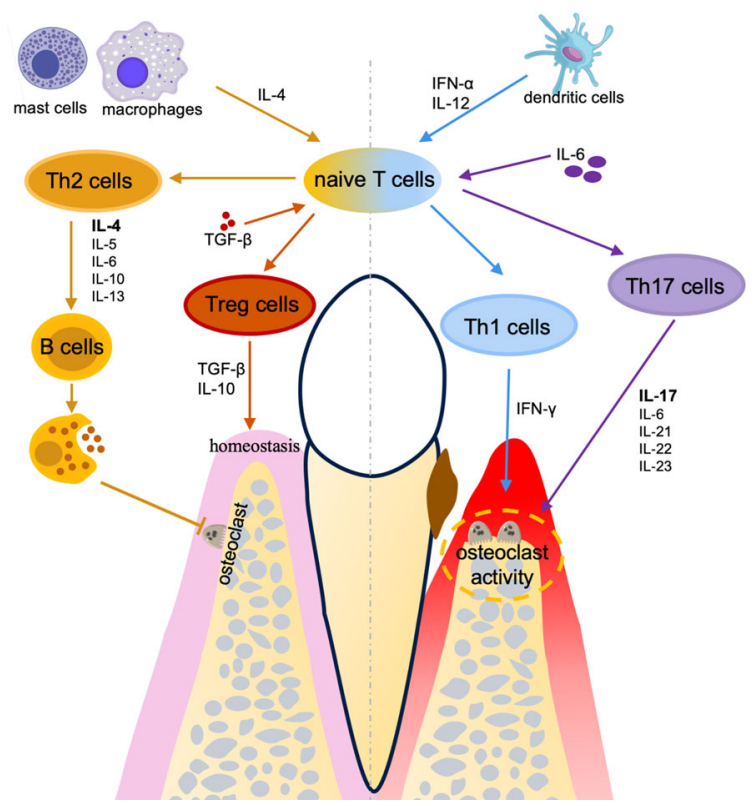

FIGURE 2 | The effects of CD4 ${ }^{+}$T cells in periodontal diseases. A homeostasis of $\mathrm{T}$ helper subsets between pro-inflammation (Th1/Th17) and anti-inflammation (Th2/Treg) plays a critical role in the pathogenesis and therapies for periodontal diseases. that $\mathrm{T}$ cells may promote osteoclastogenesis in an early stage of osteolysis, while subsequently osteoclasts may provide negative feedback: inhibit $\mathrm{CD}^{+}$effector T cells, block osteoclastogenesis, suppress osteoclast activity, and suppress bone resorption by FoxP3 $^{+} \mathrm{CD}^{+} \mathrm{T}$ cells $(85-87)$. Such negative feedback has also been found in periodontitis and $\mathrm{FoxP}^{+} \mathrm{CD}^{+} \mathrm{T}$ cells protect alveolar bone through reducing osteoclastogenesis and regulating the local immune response (88).

In contrast, Th2 cells may have protective effects on periodontal diseases by immunoregulatory and alveolar bone protection. Th2 development is induced by IL-4 (89) which is produced by the naive $\mathrm{T}$ cells or the mast cells/macrophages. Activated Th2 cells secrete IL-4, IL-5, IL-6, IL-10, and IL-13 to mediate the humoral immunity $(90)$ by promoting B cell proliferation, differentiation, and antibody production, which has been proved to restrain osteoclastogenesis (91) and downregulate pro-inflammatory cytokines (45) (Figure 2). Cavalla et al. found the cooperation between Th2 and Treg cells which provides an anti-inflammatory and pro-reparative environment that contributes to periodontal lesion stability (83). Besides, IL-4 is the only cytokine under-expressed in periodontitis individuals but elevated after periodontal treatment (92), indicating that IL-4 and Th2 cells may have positive effects on periodontal diseases.

Despite the Th1/Th2 paradigm being a dogma to describe the development of inflammatory diseases for a long period (93), another subgroup of Th cells producing IL-17 is identified, which modified Th1/Th2 paradigm (94). Th17 cells are later found to be an essential mediator for bone destruction in periodontal diseases $(95,96)$. Homeostatic oral Th17 cells are commensalindependent and IL-6-dependent, whereas the development and maintenance of Th17 cell-associated periodontal diseases is largely dependent upon the local microbiomes and require a pro-inflammatory microenvironment (97). Many proinflammatory cytokines, including IL-1 $\beta$, IL-6, IL-21, IL-22, IL-23, and IL-17, take part in the pathogenesis of periodontal diseases (98) (Figure 2). These cytokines are either stimulated or balanced by the Th17 cell-associated immune responses. Inhibiting the IL-6 signaling in dendritic cells induces a significant decrease of the Th17 cells (96). In addition, IL-17 inhibits the expression of osteoprotegerin and promotes the expression of receptor activator for nuclear factor- $\mathrm{\kappa B}$ ligand (RANKL) in periodontal ligament cells, which are two essential factors for osteoclastogenesis. Thus, IL-17 may have a destructive effect on periodontal bone remodeling (99). Besides, patients with TH17 cell defects presented diminished periodontal inflammation and alveolar bone loss, despite the increased recurrence of oral fungal infections (97). It is also clear that excessive activation of Th17 leads to connective tissue destruction and bone resorption (96). Pathogenic TH17 cells in bone resorption are converted from exFoxp $3^{+} \mathrm{T}$ cells (100). Recently, the bone damage and tooth loss induced by exFoxp $3^{+}$ TH17 cells are considered to be used for protecting against bacteria and stopping local infection, which means TH17 cells function as a two-edged sword by protecting against infection while inducing bone tissue resorption (100). 
Treg cells play a vital role in maintaining immune homeostasis (101). Treg cells development is induced in the presence of TGF- $\beta$. Besides, in the absence of IL- 6 and IL-1, the development is promoted by IL-2 and retinoic acid (RA) (93). Treg cells secrete TGF- $\beta$ and IL-10 which are critical for the regulation of inflammatory responses (93) (Figure 2). Nan Ge et al. found that Treg cells are negatively associated with the expression levels of RANKL and the number of osteoclasts in periodontitis patients (102). It has been shown that the imbalance between Th17 and Treg cells accounts for the major pathogenesis of chronic periodontal diseases whereas Treg cells are usually considered to have a protective role $(103,104)$. Compared to healthy individuals, periodontitis patients have a decreased expression level of Treg cell-related gene Foxp3 and increased levels of Th17 cell-related genes RAR-related orphan receptor C (Rorc) and IL-17A (103). Moreover, the variation of the microenvironment can change the inflammatory cytokine milieu and reshape the adaptive immune response (105). Both Treg and Th17 cells can transdifferentiate into IFN- $\gamma$-producing Th1-like cells $(105,106)$. Collectively, homeostasis of T helper subsets between pro-inflammation (Th1/Th17) and antiinflammation (Th2/Treg) plays a critical role in the pathogenesis and therapies for periodontal diseases. Although a certain understanding of the role of different $\mathrm{CD}^{+} \mathrm{T}$ cell subsets in periodontal diseases is achieved, further studies are still in progress for the identification of the core mechanisms that regulate the differentiation and activation of $\mathrm{CD} 4^{+} \mathrm{T}$ helper cells. Discovering the crucial pathways to control the differentiation of $\mathrm{CD}^{+} \mathrm{T}$ cells may bring a new direction for the treatment of periodontal diseases through regulating immunity and achieving a balance between fighting infection and reducing the tissue destruction in periodontitis.

Th22 and Th9 cells have been identified as new Th cells subsets which are phenotypically distinct from other Th cells (107, 108). Th22 cells mainly secrete IL-22 which is also produced by Th17 cells, but Th22 cells hardly produce IL-17 (109). IL-22 produced by Th22 cells are associated with alveolar bone resorption and the severity of periodontitis (110). Th9 has a potential role in tissue healing by downregulating the differentiation of Th1, Th17, and Th22 cells $(111,112)$. When Th9 cells were overexpressed, Th17 cells would decrease with decreased bone resorption (110). In general, the Th1/Th17/Th22 and Th2/Th9/Treg axis play antagonistic roles in periodontitis: the Th1/Th17/Th22 axis is related to the periodontal tissue destruction and alveolar bone loss during active periodontitis while the Th2/Th9/Treg axis is relevant to periodontitis remission, which is consistent with the data in other bone disorders (113).

\section{THE ROLE OF mTOR SIGNALING IN CD4 ${ }^{+}$ T CELL DIFFERENTIATION AND ACTIVATION}

The serine/threonine protein kinase mammalian target of rapamycin (mTOR) signaling is critical for the modulation of immune responses (114). mTOR is a downstream target of the phosphatidylinositol 3-kinase-related kinase family (115), in which mTOR serves as a main component of two protein complexes, mTOR complex 1 (mTORC1) and mTORC2, exhibiting different functions and regulating different cellular processes (116). The mTORC1 is composed of mTOR, regulatory-associated protein of mTOR (Raptor), mammalian lethal with SEC13 protein 8 (mLST8, also known as G $\beta \mathrm{L}$ ), PRAS40, and DEP domain-containing mTOR-interacting protein (DEPTOR) $(117,118)$. The mTORC2 consists of seven protein subunits: the mTOR, Rapamycin-insensitive companion of mTOR (Rictor), mammalian stress-activated protein kinase interacting protein 1 (mSIN1), protein observed with Rictor 1 and 2 (Protor1/2), DEPTOR, mLST8, and TTI1/TEL2 (119, 120). It is recognized that mTOR signaling dictates $\mathrm{T}$ cell fate through interaction and balance between mTORC1 and mTORC2 (121). mTOR signaling controls the function of dendritic cells (DCs), which are the antigen-presenting cells that encounter and capture oral microbes and then migrate to lymph nodes to regulate the differentiation of $\mathrm{CD}^{+}{ }^{+} \mathrm{T}$ cells. Specifically, mTOR inhibition has suppressive effects on DC differentiation and maturation $(114,122)$. mTOR pathway also plays a critical role in regulating $\mathrm{T}$ cell activation and differentiation. The blockade of mTOR signaling leads to significant thymic involution and a decreased T-cell output (123). In addition, suppression of mTOR cascades during $\mathrm{T}$ cell activation also causes immunosuppression (114). These findings point out the role of mTOR signaling in regulating $\mathrm{CD}^{+} \mathrm{T}$ cell activation and differentiation for periodontal tissue homeostasis.

Both mTORC1 and mTORC2 promote Th1 cell differentiation via modulating cytokine signaling (124, 125). Without the mTORC1 activator Rheb (Ras homolog enriched in brain), $\mathrm{CD}^{+} \mathrm{T}$ cells are unable to secrete IFN- $\gamma$ under Th1 polarizing condition (126). The mTORC1 could regulate Th1 differentiation by controlling the phosphorylation of canonical Th1 transcription factor T-bet (T-box expressed in T cells) (126). With defective mTORC2 signaling, naïve $\mathrm{T}$ cells show an impaired ability to differentiate into Th1 cells (125). Complementation with active Akt, an upstream kinase of mTOR complexes, can restore the expression of T-bet and thus, the Th1 cell differentiation (125). Besides, mTORC1 and mTORC2 inhibit the suppressor of cytokine signaling (SOCS) proteins (124). Rheb deficiency reduces mTORC1 activation in T cells, and Rheb-deficient T cells are unable to develop into Th1 cells (124). Knockdown of SOCS3 in Rheb-deficient $\mathrm{T}$ cells significantly increases Th1 cell differentiation, further indicating the direct role of mTORC1 cascade in Th1 cell selection and immune homeostasis (124).

mTORC2, but not mTORC1, signaling is required for Th2 cell differentiation $(124,125)$. Rictor is a crucial adaptor protein for mTORC2 whose deletion in $\mathrm{CD}^{+}$lineage cells leads to a deficiency in Th2 cell differentiation (124). Complementation experiments in the Rictor knockout $\mathrm{T}$ cells show the activation of PKC- $\theta$ via GATA3 (GATA binding protein 3) transcription factor and restoration of Th2 differentiation (127). Similarly, the knockdown of SOCS5 in Rictor-deficient T cells can result in an 
increased Th2 differention (124). As Rheb-deficient T cells retain the ability to generate Th2 cells (124), consequently, both mTORC1 and mTORC2 may involve in Th1 differentiation, while mTORC2 is required to maintain the Th2 cell homeostasis (Figures 3A, B).

mTORC1 is primary signaling required for Th17 cell differentiation. The PI3K-Akt-mTORC1-S6K1/2 axis is required for inducible Th17 cell differentiation $(128,129)$, in which depletion of Rheb in $\mathrm{CD}^{+}$lineage cells significantly decreases the differentiation of Th17 cells (124) (Figure 3C). Furthermore, the mTOR-STAT3 signaling also participates in Th17 differentiation $(130,131)$. STAT3 activation promotes the IL-17 expression by binding to the promoter regions of the IL-17 gene which leads to histone modifications of enhancer element and the expression of IL-17 increase (131). The $\mathrm{Ca}^{2+}-\mathrm{CaMK}_{4}$ Akt-mTOR axis has also been reported to be involved in Th17 differentiation (132). As the PI3K-Akt-mTOR pathway regulates multiple subsets of CD4 ${ }^{+} \mathrm{T}$ cells, $\mathrm{CaMK}_{4}$ is restricted to Th17 cell differentiation, indicating that $\mathrm{CaMK}_{4}$ may be a specific target for Th17 homeostasis (132). Despite it being widely accepted that mTORC1 is dominant signaling to promote Th17 cell differentiation, mTORC2 may also be critical for Th17 cell differentiation under special conditions, such as without the help of IL-23 (133). While deletion of Rictor in CD4 ${ }^{+}$ lineage cells has no influence on Th17 differentiation (125), the role of mTORC2 cascade in Th17 cell differentiation is still controversial.

For Treg cells, both mTORC1 and mTORC2 show inhibitory effects on the induction of Treg cells through different downstream mechanisms $(121,134)$. It has been reported that disruption of mTORC1 signaling results in preferential differentiation of naive $\mathrm{T}$ cells into Treg cells (121). The PI3K-PDK1-Akt signaling activates mTORC1 activity through inhibiting the Tsc1/Tsc2 repressor complex, leading to the activation of mTORC1 downstream phosphorylation of $\mathrm{S} 6 \mathrm{~K}$ and $4 \mathrm{E}-\mathrm{BP} 1$ to regulate Treg cell proliferation and differentiation (124, 134). Moreover,
mTORC2-Akt-FoxO1/3a signaling inhibits the differentiation of Treg cells (135). These data reveal the roles of mTORC1 and mTORC2 in Treg cell differentiation via distinctive regulatory mechanisms (Figure 3D).

In summary, Th1 and Th17 cells are mainly considered to be associated with periodontal lesion progression and alveolar bone resorption, while Th2 and Treg cells are found to have roles in immunoregulatory and alveolar bone protection. Since mTOR signaling could promote Th1 and Th17 cell differentiation and inhibit Treg commitment through different mTOR complexes, we anticipate a disadvantageous effect of mTOR signaling on periodontal diseases though regulating $\mathrm{CD}^{+} \mathrm{T}$ cell subsets, though the influence of mTOR signaling on Th22 and Th9 is not clear yet.

\section{THE POTENTIAL ROLES OF MTOR SIGNALING IN THE PATHOGENESIS OF PERIODONTAL DISEASES}

Several studies have revealed that mTOR signaling has an adverse influence on aging-related periodontal disease (136, 137). The elderly have increased susceptibility to periodontal diseases and the aging periodontal tissue tends to react violently to periodontal pathogens $(138,139)$. Aging might cause increased susceptibility to periodontitis through alteration of inflammatory status and innate immunity of the host (139), but the clinical symptoms, pathological changes and pathogenic factors in aging periodontitis are similar to general periodontitis. The inhibition of mTOR signaling could relieve inflammation by down-regulating the expression levels of IL-6 and IL- 8 in the aging periodontium (136). Additionally, the inhibition of mTOR with rapamycin treatment has been reported to prevent or reverse age-associated alveolar bone loss (137). Activation of mTOR signaling by ethanol stimulation

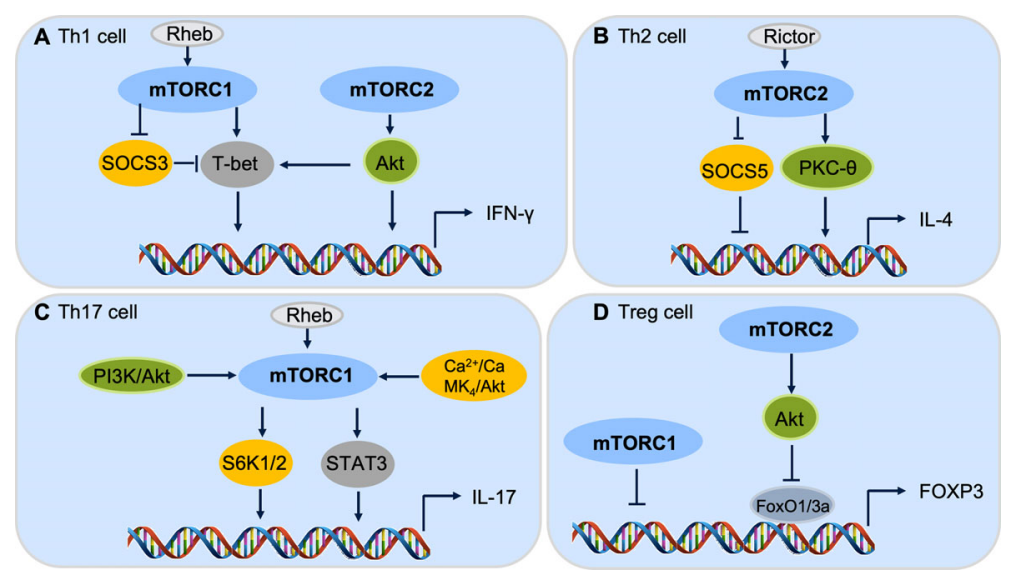

FIGURE 3 | mTOR complexes control CD4 ${ }^{+}$T cell differentiation. (A) Both mTORC1 and mTORC2 pathways are involved in Th1 cell differentiation. (B) mTORC2, but not mTORC1, cascade regulates Th2 cell differentiation. (C) mTORC1 is critical for Th17 cell differentiation through downstream S6k or STAT3 signaling. (D) Both mTORC1 and mTORC2 cascades are important to repress Foxp3 expression and Treg cell differentiation. 
could suppress human dental pulp cell differentiation and mineralization (140), while rapamycin-induced inhibition of mTOR signaling significantly diminishes odontoblastic differentiation and mineralization (140). However, whether mTOR signaling is involved in periodontitis through regulating $\mathrm{CD} 4^{+} \mathrm{T}$ cell differentiation remains unknown. Given the extensive roles of $\mathrm{mTOR}$ signaling in regulating $\mathrm{CD} 4^{+} \mathrm{T}$ subset differentiation, further studies are required to reveal the role of mTOR cascades in the pathogenesis of periodontitis, which may provide a novel therapeutic avenue to treat periodontitis that is currently lacking effective treatment procedures in the clinic (Figure 4A). There are medicines targeting the mTOR-signaling which have already been used in clinical for treating cancers $(141,142)$ and may be beneficial for the treatment of periodontitis in the future.

In addition to directly guiding $\mathrm{T}$ cell differentiation, $\mathrm{mTOR}$ signaling also has an important role in regulating cell metabolic pathways, including glycolysis, fatty acid synthesis, and inhibition of autophagy $(143,144)$ mTORC1 and mTORC2 generally promote the anabolic response, such as stimulating glycolysis, protein synthesis, and lipid metabolism to influence T cell proliferation and survival, as well as hematopoietic stem cell maintenance and differentiation (143). Deactivation of the mTOR pathway maintains $\mathrm{T}$ cell homeostasis under immune activation by optimizing antigen presentation and memory $\mathrm{T}$ cell generation (143). The asymmetric inheritance of mTOR cascades influences naive $\mathrm{CD}^{+} \mathrm{T}$ cell glycolytic metabolic capacity and cell fate determination (145). T cells with high mTORC1 activity are shown to have raised glycolytic flux and generate $\mathrm{T}$ cell populations with augmented effector capacity, whereas $\mathrm{T}$ cells with lower mTORC1 activity exhibit increased lipid metabolism and generate long-lived memory $\mathrm{T}$ cells (146) (Figure 4B). Although the role of $\mathrm{CD}^{+} \mathrm{T}$ cells in periodontitis is less obvious, $\mathrm{CD}^{+} \mathrm{T}$ cells of gingival tissues show regulatory/ suppressor properties, which are critical for the gingival tissue integrity as they initiate tissue repair mechanisms under injuries and down-regulate inflammation for tissue homeostasis (147).

Autophagy is a highly controlled biological process characterized by the degradation of cellular organelles, cytoplasm, lipids, or proteins under nutrient deprivation or stressed situations (148). The mTOR signaling, specifically mTORC1, is directly involved in the formation of autophagic vesicles (144). When nutrients are abundant, the mTORC1 phosphorylates inhibitory sites on the Unc-51 like kinase-1 (ULK1) and the adapter protein autophagy-related gene-13 (Atg13), thus restraining the induction of autophagy. In starvation, mTORC1 dissociates from the ULK1 and releases ULK1 to directly phosphorylate Atg13 for the induction of autophagy $(148,149)$. Deletion of Atg7, a critical autophagic gene, in mature circulating T cells leads to survival defect (150). Furthermore, after TCR stimulation, the Atg5-deleted T cells are not able to proliferate and undergo apoptosis (151), indicating that autophagy is indispensable for the survival and active homeostasis of resting immunological naive T cells (150), in which Th2 cells show a higher level of autophagy than Th1 cells in vitro (152). Since autophagy is inhibited by mTORC1, the ability of Rheb-deficient $\mathrm{CD} 4{ }^{+} \mathrm{T}$ cells to differentiate into Th2 cells might be promoted by the ability to utilize autophagy (17). More importantly, autophagy is critical in the pathogenesis and progress of periodontitis, in which periodontal pathogen invasion is controlled by autophagy. Autophagy can act through inactivation and elimination of intracellular pathogens (153), whereas periodontal pathogens such as $P$. gingivalis can induce autophagy (154). It is generally believed that autophagy is a negative controller of inflammasome activation (155-157) and has a protective role on periodontal tissues (158). As autophagy is inhibited by mTORC1, the negative effect of mTOR signaling on periodontitis may go through autophagic regulation (Figure 4C). The exact roles of mTOR-autophagy cascades on the initiation and progression of periodontitis still need to be evaluated through further studies.

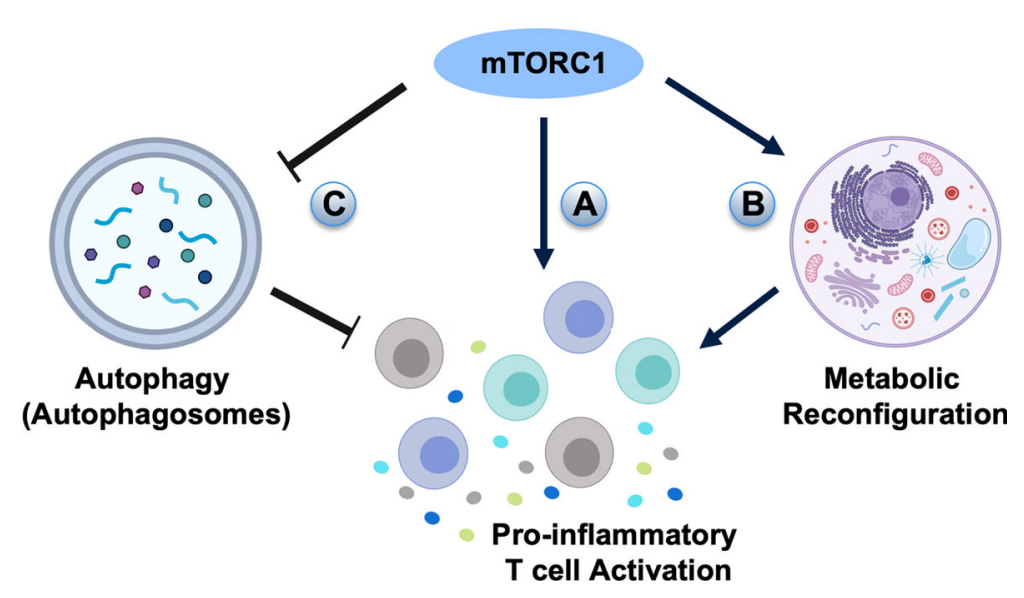

FIGURE 4 | The potential roles of mTOR signaling in the pathogenesis of periodontal diseases. (A) mTORC1 signaling may directly activate pro-inflammatory T cell differentiation in periodontal diseases. (B) High mTORC1 activity elevates glycolytic flux and generates T cell populations with enhanced effector capacity. (C) As autophagy is inhibited by mTORC1, the negative effect of mTOR signaling on periodontitis may go through autophagic regulation. 


\section{PROSPECTIVE}

Periodontal disease is triggered by the microorganisms and the resulting activation of the host immune responses (159). The immune responses which are responsible for protection against infection can also cause periodontal tissue destruction (11). Adapting the local host immune responses, regulated by $\mathrm{CD} 4^{+}$ $\mathrm{T}$ cells, is a potential mechanism for interfering with the pathogenesis of periodontal diseases. Strategies for regulating $\mathrm{CD}^{+}{ }^{+} \mathrm{T}$ cell differentiation and activation might be the potential therapeutic targets for periodontal bone regeneration. This may include the regulation of $\mathrm{mTOR}$ signaling, which is crucial for $\mathrm{CD}^{+} \mathrm{T}$ cell differentiation. Since different mTOR complexes play distinctive roles on $\mathrm{CD} 4{ }^{+} \mathrm{T}$ cell fate determination, explicit deletion or activation of mTORC1 and mTORC2 has been recommended to explore their exact roles on periodontitis. Current studies exploring the influences of mTOR signaling on aging periodontium do not distinguish the roles of $\mathrm{mTORC} 1$ and mTORC2, nor do they explain the possible mTOR downstream targets, such as metabolic pathways and the autophagic regulations to control $\mathrm{T}$ cell differentiation (136, 137). Thus, further studies are necessary for this field to find the underlying mechanisms of $\mathrm{CD}^{+} \mathrm{T}$ cell-mediated immune responses. In

\section{REFERENCES}

1. Tonetti MS, Cortellini P, Pellegrini G, Nieri M, Bonaccini D, Allegri M, et al. Xenogenic Collagen Matrix or Autologous Connective Tissue Graft as Adjunct to Coronally Advanced Flaps for Coverage of Multiple Adjacent Gingival Recession: Randomized Trial Assessing non-Inferiority in Root Coverage and Superiority in Oral Health-Related Quality of Life. J Clin periodontol (2018) 45(1):78-88. doi: 10.1111/jcpe.12834

2. Lim G, Janu U, Chiou LL, Gandhi KK, Palomo L, John V. Periodontal Health and Systemic Conditions. Dent J (2020) 8(4):130. doi: 10.3390/dj8040130

3. Könönen E, Gursoy M, Gursoy UK. Periodontitis: A Multifaceted Disease of Tooth-Supporting Tissues. J Clin Med (2019) 8(8):1135. doi: 10.3390/jcm8081135

4. Liccardo D, Cannavo A, Spagnuolo G, Ferrara N, Cittadini A, Rengo C, et al. Periodontal Disease: A Risk Factor for Diabetes and Cardiovascular Disease. Int J Mol Sci (2019) 20(6):1414. doi: 10.3390/ijms20061414

5. Wazir SS, Arora P, Ghosh S, Bhagat V, Khurana S, Mahanta S. Influence of Maternal Periodontal Health as a Risk Factor for Low-Birth-Weight Infants in Terai Population of Nepal. J Educ Health Promot (2019) 8:233. doi: 10.4103/jehp.jehp_408_18

6. Schmidlin PR, Khademi A, Fakheran O. Association Between Periodontal Disease and Non-Apnea Sleep Disorder: A Systematic Review. Clin Oral Invest (2020) 24(10):3335-45. doi: 10.1007/s00784-020-03475-2

7. Colombo AP, Boches SK, Cotton SL, Goodson JM, Kent R, Haffajee AD, et al. Comparisons of Subgingival Microbial Profiles of Refractory Periodontitis, Severe Periodontitis, and Periodontal Health Using the Human Oral Microbe Identification Microarray. J Periodontol (2009) 80 (9):1421-32. doi: 10.1902/jop.2009.090185

8. Ebersole JL, Dawson DR3rd, Morford LA, Peyyala R, Miller CS, Gonzaléz OA. Periodontal Disease Immunology: 'Double Indemnity' in Protecting the Host. Periodontol 2000 (2013) 62(1):163-202. doi: 10.1111/prd.12005

9. Figueredo CM, Lira-Junior R, Love RM. T and B Cells in Periodontal Disease: New Functions in A Complex Scenario. Int J Mol Sci (2019) 20(16). doi: 10.3390/ijms20163949

10. Hathaway-Schrader JD, Novince CM. Maintaining Homeostatic Control of Periodontal Bone Tissue. Periodontol 2000 (2021) 86(1):157-87. doi: $10.1111 /$ prd.12368

11. Silva N, Abusleme L, Bravo D, Dutzan N, Garcia-Sesnich J, Vernal R, et al. Host Response Mechanisms in Periodontal Diseases. J Appl Oral Sci Rev FOB (2015) 23(3):329-55. doi: 10.1590/1678-775720140259 addition, novel targets are required to be explored for regulating immunological networks in periodontal diseases. It will provide a better understanding of the disease and the development of novel therapeutic strategies for periodontal tissue regeneration and periodontitis treatment.

\section{AUTHOR CONTRIBUTIONS}

Conceptualization, CC, QJ, and XH. Writing - Original Draft Preparation, QJ, XH, WY, and CC. Writing - Review \& Editing, QJ, XH, WY, RH, XZ, and CC. All authors contributed to the article and approved the submitted version.

\section{FUNDING}

This work was supported by grants from National Institute of Dental and Craniofacial Research, National Institutes of Health, Department of Health and Human Services (R00DE025915, R03DE028026, and R01DE027901 to CC), and a Colgate Palmolive Grant (A-2019-590-OC) to CC.

12. Sun L, Girnary M, Wang L, Jiao Y, Zeng E, Mercer K, et al. IL-10 Dampens an IL-17-Mediated Periodontitis-Associated Inflammatory Network. J Immunol (Baltimore Md 1950) (2020) 204(8):2177-91. doi: 10.4049/ jimmunol.1900532

13. Szczepaniak P, Mikołajczyk TP, Cześnikiewicz-Guzik M, Guzik TJ. Periodontitis as an Inflammatory Trigger in Hypertension: From Basic Immunology to Clinical Implications. Kardiologia Polska (2021) 79 (11):1206-14. doi: 10.33963/KP.a2021.0161

14. Teng YT, Nguyen H, Gao X, Kong YY, Gorczynski RM, Singh B, et al. Functional Human T-Cell Immunity and Osteoprotegerin Ligand Control Alveolar Bone Destruction in Periodontal Infection. J Clin Invest (2000) 106 (6):R59-67. doi: 10.1172/jci10763

15. Nakajima T, Ueki-Maruyama K, Oda T, Ohsawa Y, Ito H, Seymour GJ, et al. Regulatory T-Cells Infiltrate Periodontal Disease Tissues. J Dental Res (2005) 84(7):639-43. doi: 10.1177/154405910508400711

16. Hirahara K, Nakayama T. CD4+ T-Cell Subsets in Inflammatory Diseases: Beyond the Th1/Th2 Paradigm. Int Immunol (2016) 28(4):163-71. doi: 10.1093/intimm/dxw006

17. Waickman AT, Powell JD. mTOR, Metabolism, and the Regulation of T-Cell Differentiation and Function. Immunol Rev (2012) 249(1):43-58. doi: 10.1111/j.1600-065X.2012.01152.x

18. Huang H, Long L, Zhou P, Chapman NM, Chi H. mTOR Signaling at the Crossroads of Environmental Signals and T-Cell Fate Decisions. Immunol Rev (2020) 295(1):15-38. doi: 10.1111/imr.12845

19. Hajishengallis G. Periodontitis: From Microbial Immune Subversion to Systemic Inflammation. Nat Rev Immunol (2015) 15(1):30-44. doi: $10.1038 /$ nri3785

20. Genco RJ, Sanz M. Clinical and Public Health Implications of Periodontal and Systemic Diseases: An Overview. Periodontol 2000 (2020) 83(1):7-13. doi: $10.1111 /$ prd.12344

21. Stafford G, Sharma A. Periodontal Pathogen Sialometabolic Activity in Periodontitis Emerg Ther Periodontics. (2020) 187-94. doi: 10.1007/978-3030-42990-4_12

22. Seneviratne CJ, Zhang CF, Samaranayake LP. Dental Plaque Biofilm in Oral Health and Disease. Chin J Dental Res Off J Sci Sect Chin Stomatological Assoc (CSA) (2011) 14(2):87-94.

23. Hajishengallis G. Immunomicrobial Pathogenesis of Periodontitis: Keystones, Pathobionts, and Host Response. Trends Immunol (2014) 35 (1):3-11. doi: 10.1016/j.it.2013.09.001 
24. Socransky SS, Haffajee AD, Cugini MA, Smith C, Kent RLJr. Microbial Complexes in Subgingival Plaque. J Clin Periodontol (1998) 25(2):134-44. doi: 10.1111/j.1600-051x.1998.tb02419.x

25. Valm AM. The Structure of Dental Plaque Microbial Communities in the Transition From Health to Dental Caries and Periodontal Disease. J Mol Biol (2019) 431(16):2957-69. doi: 10.1016/j.jmb.2019.05.016

26. Dahlen G, Basic A, Bylund J. Importance of Virulence Factors for the Persistence of Oral Bacteria in the Inflamed Gingival Crevice and in the Pathogenesis of Periodontal Disease. J Clin Med (2019) 8(9):1339. doi: $10.3390 / \mathrm{jcm} 8091339$

27. Page RC, Kornman KS. The Pathogenesis of Human Periodontitis: An Introduction. Periodontol 2000 (1997) 14:9-11. doi: 10.1111/j.16000757.1997.tb00189.x

28. Aghaloo T, Kim JJ, Gordon T, Behrsing HP. In Vitro Models, Standards, and Experimental Methods for Tobacco Products. Adv Dental Res (2019) 30 (1):16-21. doi: 10.1177/0022034519872474

29. Leite FRM, Nascimento GG, Scheutz F, López R. Effect of Smoking on Periodontitis: A Systematic Review and Meta-Regression. Am J Prev Med (2018) 54(6):831-41. doi: 10.1016/j.amepre.2018.02.014

30. Yılmaz Şaştım Ç, Gürsoy M, Könönen E, Kasurinen A, Norvio S, Gürsoy UK, et al. Salivary and Serum Markers of Angiogenesis in Periodontitis in Relation to Smoking. Clin Oral Invest (2021) 25(3):1117-26. doi: 10.1007/ s00784-020-03411-4

31. Gajendran PL, Parthasarathy H, Tadepalli A. Comparative Evaluation of Cathepsin K Levels in Gingival Crevicular Fluid Among Smoking and Nonsmoking Patients With Chronic Periodontitis. Indian J Dental Res Off Publ Indian Soc Dental Res (2018) 29(5):588-93. doi: 10.4103/ ijdr.IJDR_95_17

32. Tonetti MS, Greenwell H, Kornman KS. Staging and Grading of Periodontitis: Framework and Proposal of a New Classification and Case Definition. J Periodontol (2018) 89(Suppl 1):S159-s72. doi: 10.1002/jper.18-0006

33. Kanmaz M, Kanmaz B, Buduneli N. Periodontal Treatment Outcomes in Smokers: A Narrative Review. Tob Induc Dis (2021) 19:77-. doi: 10.18332/ tid/142106

34. Holde GE, Jönsson B, Oscarson N, Müller HP. To What Extent Does Smoking Affect Gingival Bleeding Response to Supragingival Plaque? SiteSpecific Analyses in a Population-Based Study. J Periodontal Res (2020) 55 (2):277-86. doi: 10.1111/jre.12713

35. Mirbod SM, Ahing SI, Pruthi VK. Immunohistochemical Study of Vestibular Gingival Blood Vessel Density and Internal Circumference in Smokers and non-Smokers. J periodontol (2001) 72(10):1318-23. doi: 10.1902/ jop.2001.72.10.1318

36. Duarte PM, Nogueira CFP, Silva SM, Pannuti CM, Schey KC, Miranda TS. Impact of Smoking Cessation on Periodontal Tissues. Int Dental J (2021) 72 (1):31-6. doi: 10.1016/j.identj.2021.01.016

37. Souto MLS, Rovai ES, Villar CC, Braga MM, Pannuti CM. Effect of Smoking Cessation on Tooth Loss: A Systematic Review With Meta-Analysis. BMC Oral Health (2019) 19(1):245. doi: 10.1186/s12903-019-0930-2

38. Nibali L, Bayliss-Chapman J, Almofareh SA, Zhou Y, Divaris K, Vieira AR. What Is the Heritability of Periodontitis? A Systematic Review. J Dental Res (2019) 98(6):632-41. doi: 10.1177/0022034519842510

39. Jurdziński KT, Potempa J, Grabiec AM. Epigenetic Regulation of Inflammation in Periodontitis: Cellular Mechanisms and Therapeutic Potential. Clin Epigenet (2020) 12(1):186. doi: 10.1186/s13148-020-00982-7

40. Bui FQ, Almeida-da-Silva CLC, Huynh B, Trinh A, Liu J, Woodward J, et al. Association Between Periodontal Pathogens and Systemic Disease. Biomed J (2019) 42(1):27-35. doi: 10.1016/j.bj.2018.12.001

41. Graves DT, Ding Z, Yang Y. The Impact of Diabetes on Periodontal Diseases. Periodontol 2000 (2020) 82(1):214-24. doi: 10.1111/prd.12318

42. Jung ES, Choi YY, Lee KH. Relationship Between Rheumatoid Arthritis and Periodontal Disease in Korean Adults: Data From the Sixth Korea National Health and Nutrition Examination Survey, 2013 to 2015. J Periodontol (2019) 90(4):350-7. doi: 10.1002/jper.18-0290

43. Renvert S, Berglund JS, Persson GR, Söderlin MK. The Association Between Rheumatoid Arthritis and Periodontal Disease in a Population-Based CrossSectional Case-Control Study. BMC Rheumatol (2020) 4:31. doi: 10.1186/ s41927-020-00129-4
44. Kinane DF, Demuth DR, Gorr SU, Hajishengallis GN, Martin MH. Human Variability in Innate Immunity. Periodontol 2000 (2007) 45:14-34. doi: 10.1111/j.1600-0757.2007.00220.x

45. Cekici A, Kantarci A, Hasturk H, Van Dyke TE. Inflammatory and Immune Pathways in the Pathogenesis of Periodontal Disease. Periodontol 2000 (2014) 64(1):57-80. doi: 10.1111/prd.12002

46. Tracey KJ. The Inflammatory Reflex. Nature (2002) 420(6917):853-9. doi: 10.1038/nature01321

47. Janeway CAJr., Medzhitov R. Innate Immune Recognition. Annu Rev Immunol (2002) 20:197-216. doi: 10.1146/annurev.immunol.20.083001.084359

48. Hirai K, Furusho H, Kawashima N, Xu S, de Beer MC, Battaglino R, et al. Serum Amyloid A Contributes to Chronic Apical Periodontitis via TLR2 and TLR4. J Dental Res (2019) 98(1):117-25. doi: 10.1177/0022034518796456

49. Benakanakere M, Kinane DF. Innate Cellular Responses to the Periodontal Biofilm. Front Oral Biol (2012) 15:41-55. doi: 10.1159/000329670

50. Goulopoulou S, McCarthy CG, Webb RC. Toll-Like Receptors in the Vascular System: Sensing the Dangers Within. Pharmacol Rev (2016) 68 (1):142-67. doi: $10.1124 /$ pr.114.010090

51. Mahanonda R, Pichyangkul S. Toll-Like Receptors and Their Role in Periodontal Health and Disease. Periodontol 2000 (2007) 43:41-55. doi: 10.1111/j.1600-0757.2006.00179.x

52. Zoellner H, Chapple CC, Hunter N. Microvasculature in Gingivitis and Chronic Periodontitis: Disruption of Vascular Networks With Protracted Inflammation. Microsc Res Tech (2002) 56(1):15-31. doi: 10.1002/ jemt.10009

53. Kasprzak A, Surdacka A, Tomczak M, Konkol M. Role of High Endothelial Postcapillary Venules and Selected Adhesion Molecules in Periodontal Diseases: A Review. J Periodontal Res (2013) 48(1):1-21. doi: 10.1111/ j.1600-0765.2012.01492.x

54. Graves DT, Kang J, Andriankaja O, Wada K, Rossa CJr. Animal Models to Study Host-Bacteria Interactions Involved in Periodontitis. Front Oral Biol (2012) 15:117-32. doi: 10.1159/000329675

55. Gandhirajan RK, Meng S, Chandramoorthy HC, Mallilankaraman K, Mancarella S, Gao H, et al. Blockade of NOX2 and STIM1 Signaling Limits Lipopolysaccharide-Induced Vascular Inflammation. J Clin Invest (2013) 123(2):887-902. doi: 10.1172/jci65647

56. Zhang W, Zhang Y, Guo X, Zeng Z, Wu J, Liu Y, et al. Sirt1 Protects Endothelial Cells Against LPS-Induced Barrier Dysfunction. Oxid Med Cell Longev (2017) 2017:4082102. doi: 10.1155/2017/4082102

57. Liu RK, Cao CF, Meng HX, Gao Y. Polymorphonuclear Neutrophils and Their Mediators in Gingival Tissues From Generalized Aggressive Periodontitis. J Periodontol (2001) 72(11):1545-53. doi: 10.1902/jop.2001.72.11.1545

58. Vitkov L, Hartl D, Minnich B, Hannig M. Janus-Faced Neutrophil Extracellular Traps in Periodontitis. Front Immunol (2017) 8:1404. doi: 10.3389/fimmu.2017.01404

59. Wallet SM, Puri V, Gibson FC. Linkage of Infection to Adverse Systemic Complications: Periodontal Disease, Toll-Like Receptors, and Other Pattern Recognition Systems. Vaccines (2018) 6(2). doi: 10.3390/vaccines6020021

60. Radsak M, Iking-Konert C, Stegmaier S, Andrassy K, Hänsch GM. Polymorphonuclear Neutrophils as Accessory Cells for T-Cell Activation: Major Histocompatibility Complex Class II Restricted Antigen-Dependent Induction of T-Cell Proliferation. Immunology (2000) 101(4):521-30. doi: 10.1046/j.1365-2567.2000.00140.x

61. Campbell L, Millhouse E, Malcolm J, Culshaw S. T Cells, Teeth and Tissue Destruction - What Do T Cells Do in Periodontal Disease? Mol Oral Microbiol (2016) 31(6):445-56. doi: 10.1111/omi.12144

62. Garlet GP. Destructive and Protective Roles of Cytokines in Periodontitis: A Re-Appraisal From Host Defense and Tissue Destruction Viewpoints. J Dental Res (2010) 89(12):1349-63. doi: 10.1177/0022034510376402

63. Cochran DL. Inflammation and Bone Loss in Periodontal Disease. J periodontol (2008) 79(8 Suppl):1569-76. doi: 10.1902/jop.2008.080233

64. Mahanonda R, Champaiboon C, Subbalekha K, Sa-Ard-Iam N, Yongyuth A, Isaraphithakkul B, et al. Memory T Cell Subsets in Healthy Gingiva and Periodontitis Tissues. J Periodontol (2018) 89(9):1121-30. doi: 10.1002/ jper.17-0674

65. Mahanonda R, Champaiboon C, Subbalekha K, Sa-Ard-Iam N, Rattanathammatada W, Thawanaphong S, et al. Human Memory B Cells 
in Healthy Gingiva, Gingivitis, and Periodontitis. J Immunol (Baltimore Md 1950) (2016) 197(3):715-25. doi: 10.4049/jimmunol.1600540

66. Gruber HE. Bone and the Immune System. Proc Soc Exp Biol Med Soc Exp Biol Med (New York NY) (1991) 197(3):219-25. doi: 10.3181/00379727-197-43249

67. Bucher CH, Schlundt C, Wulsten D, Sass FA, Wendler S, Ellinghaus A, et al. Experience in the Adaptive Immunity Impacts Bone Homeostasis, Remodeling, and Healing. Front Immunol (2019) 10:797. doi: 10.3389/ fimmu.2019.00797

68. Fujihashi K, Kono Y, Beagley KW, Yamamoto M, McGhee JR, Mestecky J, et al. Cytokines and Periodontal Disease: Immunopathological Role of Interleukins for B Cell Responses in Chronic Inflamed Gingival Tissues. J Periodontol (1993) 64(5 Suppl):400-6.

69. Zou J, Carrington A, Collet B, Dijkstra JM, Yoshiura Y, Bols N, et al. Identification and Bioactivities of IFN-Gamma in Rainbow Trout Oncorhynchus Mykiss: The First Th1-Type Cytokine Characterized Functionally in Fish. J Immunol (Baltimore Md 1950) (2005) 175(4):248494. doi: 10.4049/jimmunol.175.4.2484

70. Colliou N, Ge Y, Gong M, Zadeh M, Li J, Alonzo F3rd, et al. Regulation of Th17 Cells by P. UF1 Against Systemic Listeria Monocytogenes Infection. Gut Microbes (2018) 9(3):279-87. doi: 10.1080/19490976.2017.1417731

71. Ochiai S, Jagot F, Kyle RL, Hyde E, White RF, Prout M, et al. Thymic Stromal Lymphopoietin Drives the Development of IL-13(+) Th2 Cells. Proc Natl Acad Sci USA (2018) 115(5):1033-8. doi: 10.1073/pnas.1714348115

72. Meningher T, Barsheshet Y, Ofir-Birin Y, Gold D, Brant B, Dekel E, et al. Schistosomal Extracellular Vesicle-Enclosed miRNAs Modulate Host T Helper Cell Differentiation. EMBO Rep (2020) 21(1):e47882. doi: $10.15252 / \mathrm{embr} .201947882$

73. Zhu X, Zhu J. CD4 T Helper Cell Subsets and Related Human Immunological Disorders. Int J Mol Sci (2020) 21(21):8011. doi: 10.3390/ ijms 21218011

74. Gemmell E, Yamazaki K, Seymour GJ. Destructive Periodontitis Lesions are Determined by the Nature of the Lymphocytic Response. Crit Rev Oral Biol Med an Off Publ Am Assoc Oral Biol (2002) 13(1):17-34. doi: 10.1177/ 154411130201300104

75. Nizzoli G, Krietsch J, Weick A, Steinfelder S, Facciotti F, Gruarin P, et al. Human CD1c+ Dendritic Cells Secrete High Levels of IL-12 and Potently Prime Cytotoxic T-Cell Responses. Blood (2013) 122(6):932-42. doi: 10.1182/blood-2013-04-495424

76. Gaffen SL, Hajishengallis G. A New Inflammatory Cytokine on the Block: Re-Thinking Periodontal Disease and the Th1/Th2 Paradigm in the Context of Th17 Cells and IL-17. J Dental Res (2008) 87(9):817-28. doi: 10.1177/ 154405910808700908

77. Cenci S, Toraldo G, Weitzmann MN, Roggia C, Gao Y, Qian WP, et al. Estrogen Deficiency Induces Bone Loss by Increasing T Cell Proliferation and Lifespan Through IFN-Gamma-Induced Class II Transactivator. Proc Natl Acad Sci USA (2003) 100(18):10405-10. doi: 10.1073/pnas.1533207100

78. Gao Y, Grassi F, Ryan MR, Terauchi M, Page K, Yang X, et al. IFN-Gamma Stimulates Osteoclast Formation and Bone Loss In Vivo via Antigen-Driven T Cell Activation. J Clin Invest (2007) 117(1):122-32. doi: 10.1172/jci30074

79. Takayanagi H, Ogasawara K, Hida S, Chiba T, Murata S, Sato K, et al. T-CellMediated Regulation of Osteoclastogenesis by Signalling Cross-Talk Between RANKL and IFN-Gamma. Nature (2000) 408(6812):600-5. doi: $10.1038 / 35046102$

80. Arun KV, Talwar A, Kumar TSS. T-Helper Cells in the Etiopathogenesis of Periodontal Disease: A Mini Review. J Indian Soc Periodontol (2011) 15 (1):4-10. doi: 10.4103/0972-124X.82255

81. Taubman MA, Kawai T. Involvement of T-Lymphocytes in Periodontal Disease and in Direct and Indirect Induction of Bone Resorption. Crit Rev Oral Biol Med an Off Publ Am Assoc Oral Biol (2001) 12(2):125-35. doi: $10.1177 / 10454411010120020301$

82. Tan J, Dai A, Pan L, Zhang L, Wang Z, Ke T, et al. Inflamm-Aging-Related Cytokines of IL-17 and IFN- $\gamma$ Accelerate Osteoclastogenesis and Periodontal Destruction. J Immunol Res (2021) 2021:9919024. doi: 10.1155/2021/ 9919024

83. Cavalla F, Letra A, Silva RM, Garlet GP. Determinants of Periodontal/ Periapical Lesion Stability and Progression. J Dental Res (2021) 100(1):2936. doi: $10.1177 / 0022034520952341$
84. D'Amico L, Roato I. Cross-Talk Between T Cells and Osteoclasts in Bone Resorption. BoneKEy Rep (2012) 1:82. doi: 10.1038/bonekey.2012.82

85. Buchwald ZS, Kiesel JR, DiPaolo R, Pagadala MS, Aurora R. Osteoclast Activated FoxP3+ CD8+ T-Cells Suppress Bone Resorption In Vitro. PloS One (2012) 7(6):e38199. doi: 10.1371/journal.pone.0038199

86. Srivastava RK, Dar HY, Mishra PK. Immunoporosis: Immunology of Osteoporosis-Role of T Cells. Front Immunol (2018) 9:657. doi: 10.3389/ fimmu.2018.00657

87. Roato I, Caldo D, D'Amico L, D'Amelio $\mathrm{P}$, Godio L, Patanè $\mathrm{S}$, et al. Osteoclastogenesis in Peripheral Blood Mononuclear Cell Cultures of Periprosthetic Osteolysis Patients and the Phenotype of T Cells Localized in Periprosthetic Tissues. Biomaterials (2010) 31(29):7519-25. doi: 10.1016/ j.biomaterials.2010.06.027

88. Han YK, Jin Y, Miao YB, Shi T, Lin XP. CD8(+) Foxp3(+) T Cells Affect Alveolar Bone Homeostasis via Modulating Tregs/Th17 During Induced Periodontitis: An Adoptive Transfer Experiment. Inflammation (2018) 41 (5):1791-803. doi: 10.1007/s10753-018-0822-7

89. Junttila IS. Tuning the Cytokine Responses: An Update on Interleukin (IL)-4 and IL-13 Receptor Complexes. Front Immunol (2018) 9:888. doi: 10.3389/ fimmu.2018.00888

90. Le Gros G, Ben-Sasson SZ, Seder R, Finkelman FD, Paul WE. Generation of Interleukin 4 (IL-4)-Producing Cells In Vivo and In Vitro: IL-2 and IL-4 Are Required for In Vitro Generation of IL-4-Producing Cells. J Exp Med (1990) 172(3):921-9. doi: 10.1084/jem.172.3.921

91. Hajishengallis G, Korostoff JM. Revisiting the Page \& Schroeder Model: The Good, the Bad and the Unknowns in the Periodontal Host Response 40 Years Later. Periodontol 2000 (2017) 75(1):116-51. doi: 10.1111/prd.12181

92. Stadler AF, Angst PD, Arce RM, Gomes SC, Oppermann RV, Susin C. Gingival Crevicular Fluid Levels of Cytokines/Chemokines in Chronic Periodontitis: A Meta-Analysis. J Clin Periodontol (2016) 43(9):727-45. doi: 10.1111/jcpe. 12557

93. Arun KV, Talwar A, Kumar TS. T-Helper Cells in the Etiopathogenesis of Periodontal Disease: A Mini Review. J Indian Soc Periodontol (2011) 15 (1):4-10. doi: 10.4103/0972-124x.82255

94. Tabarkiewicz J, Pogoda K, Karczmarczyk A, Pozarowski P, Giannopoulos K. The Role of IL-17 and Th17 Lymphocytes in Autoimmune Diseases. Archivum Immunologiae Ther Exp (2015) 63(6):435-49. doi: 10.1007/ s00005-015-0344-z

95. Dutzan N, Abusleme L. T Helper 17 Cells as Pathogenic Drivers of Periodontitis. Adv Exp Med Biol (2019) 1197:107-17. doi: 10.1007/978-3030-28524-1_9

96. Glowczyk I, Wong A, Potempa B, Babyak O, Lech M, Lamont RJ, et al. Inactive Gingipains From P. Gingivalis Selectively Skews T Cells Toward a Th17 Phenotype in an IL-6 Dependent Manner. Front Cell infect Microbiol (2017) 7:140. doi: 10.3389/fcimb.2017.00140

97. Dutzan N, Kajikawa T, Abusleme L, Greenwell-Wild T, Zuazo CE, Ikeuchi $\mathrm{T}$, et al. A Dysbiotic Microbiome Triggers T(H)17 Cells to Mediate Oral Mucosal Immunopathology in Mice and Humans. Sci Trans Med (2018) 10 (463):eaat0797. doi: 10.1126/scitranslmed.aat0797

98. Medara N, Lenzo JC, Walsh KA, Reynolds EC, Darby IB, O'Brien-Simpson NM. A Review of T Helper 17 Cell-Related Cytokines in Serum and Saliva in Periodontitis. Cytokine (2021) 138:155340. doi: 10.1016/j.cyto.2020.155340

99. Lin D, Li L, Sun Y, Wang W, Wang X, Ye Y, et al. IL-17 Regulates the Expressions of RANKL and OPG in Human Periodontal Ligament Cells via TRAF6/TBK1-JNK/NF-kb Pathways. Immunology (2014) 144(3):472-85. doi: $10.1111 /$ imm.12395

100. Tsukasaki M, Komatsu N, Nagashima K, Nitta T, Pluemsakunthai W, Shukunami C, et al. Host Defense Against Oral Microbiota by BoneDamaging T Cells. Nat Commun (2018) 9(1):701. doi: 10.1038/s41467018-03147-6

101. Wei L, Xu M, Xiong H. An Update of Knowledge on the Regulatory Role of Treg Cells in Apical Periodontitis. Oral Dis (2020) 27(6):1356-65. doi: 10.1111/odi.13450

102. Ge N, Peng J, Yu L, Huang S, Xu L, Su Y, et al. Orthodontic Treatment Induces Th17/Treg Cells to Regulate Tooth Movement in Rats With Periodontitis. Iranian J Basic Med Sci (2020) 23(10):1315-22. doi: $10.22038 / \mathrm{ijbms} .2020 .44437 .10419$ 
103. Leveque L, Deknuydt F, Bioley G, Old LJ, Matsuzaki J, Odunsi K, et al. Interleukin 2-Mediated Conversion of Ovarian Cancer-Associated CD4+ Regulatory T Cells Into Proinflammatory Interleukin 17-Producing Helper T Cells. I Immunother (Hagerstown Md 1997) (2009) 32(2):101-8. doi: 10.1097/CJI.0b013e318195b59e

104. Su X, Zhang J, Qin X. CD40 Up-Regulation on Dendritic Cells Correlates With Th17/Treg Imbalance in Chronic Periodontitis in Young Population. Innate Immun (2020) 26(6):482-9. doi: 10.1177/1753425920917731

105. Bittner-Eddy PD, Fischer LA, Costalonga M. Transient Expression of IL-17A in Foxp3 Fate-Tracked Cells in Porphyromonas Gingivalis-Mediated Oral Dysbiosis. Front Immunol (2020) 11:677. doi: 10.3389/fimmu.2020.00677

106. Bsat M, Chapuy L, Rubio M, Wassef R, Richard C, Schwenter F, et al. Differential Pathogenic Th17 Profile in Mesenteric Lymph Nodes of Crohn's Disease and Ulcerative Colitis Patients. Front Immunol (2019) 10:1177. doi: 10.3389/fimmu.2019.01177

107. Barnes JL, Plank MW, Asquith K, Maltby S, Sabino LR, Kaiko GE, et al. THelper 22 Cells Develop as a Distinct Lineage From Th17 Cells During Bacterial Infection and Phenotypic Stability Is Regulated by T-Bet. Mucosal Immunol (2021) 14(5):1077-87. doi: 10.1038/s41385-021-00414-6

108. Lu Y, Wang Q, Xue G, Bi E, Ma X, Wang A, et al. Th9 Cells Represent a Unique Subset of CD4(+) T Cells Endowed With the Ability to Eradicate Advanced Tumors. Cancer Cell (2018) 33(6):1048-60.e7. doi: 10.1016/ j.ccell.2018.05.004

109. Miyazaki Y, Nakayamada S, Kubo S, Nakano K, Iwata S, Miyagawa I, et al. Th22 Cells Promote Osteoclast Differentiation via Production of IL-22 in Rheumatoid Arthritis. Front Immunol (2018) 9:2901. doi: 10.3389/ fimmu.2018.02901

110. Díaz-Zúñiga J, Melgar-Rodríguez S, Rojas L, Alvarez C, Monasterio G, Carvajal P, et al. Increased Levels of the T-Helper 22-Associated Cytokine (Interleukin-22) and Transcription Factor (Aryl Hydrocarbon Receptor) in Patients With Periodontitis are Associated With Osteoclast Resorptive Activity and Severity of the Disease. J Periodontal Res (2017) 52(5):893902. doi: $10.1111 /$ jre. 12461

111. Jabeen R, Kaplan MH. The Symphony of the Ninth: The Development and Function of Th9 Cells. Curr Opin Immunol (2012) 24(3):303-7. doi: 10.1016/ j.coi.2012.02.001

112. Aranha AM, Repeke CE, Garlet TP, Vieira AE, Campanelli AP, Trombone AP, et al. Evidence Supporting a Protective Role for Th9 and Th22 Cytokines in Human and Experimental Periapical Lesions. J Endodontics (2013) 39 (1):83-7. doi: 10.1016/j.joen.2012.10.015

113. Monasterio G, Castillo F, Rojas L, Cafferata EA, Alvarez C, Carvajal P, et al. Th1/Th17/Th22 Immune Response and Their Association With Joint Pain, Imagenological Bone Loss, RANKL Expression and Osteoclast Activity in Temporomandibular Joint Osteoarthritis: A Preliminary Report. J Oral Rehabil (2018) 45(8):589-97. doi: 10.1111/joor.12649

114. Thomson AW, Turnquist HR, Raimondi G. Immunoregulatory Functions of mTOR Inhibition. Nat Rev Immunol (2009) 9(5):324-37. doi: 10.1038/nri2546

115. Mardanshahi A, Gharibkandi NA, Vaseghi S, Abedi SM, Molavipordanjani S. The PI3K/AKT/mTOR Signaling Pathway Inhibitors Enhance Radiosensitivity in Cancer Cell Lines. Mol Biol Rep (2021) 48(8):1-14. doi: 10.1007/s11033-021-06607-3

116. Jhanwar-Uniyal M, Wainwright JV, Mohan AL, Tobias ME, Murali R, Gandhi CD, et al. Diverse Signaling Mechanisms of mTOR Complexes: Mtorc1 and Mtorc2 in Forming a Formidable Relationship. Adv Biol Regul (2019) 72:51-62. doi: 10.1016/j.jbior.2019.03.003

117. Kim DH, Sarbassov DD, Ali SM, King JE, Latek RR, Erdjument-Bromage H, et al. mTOR Interacts With Raptor to Form a Nutrient-Sensitive Complex That Signals to the Cell Growth Machinery. Cell (2002) 110(2):163-75. doi: $10.1016 / \mathrm{s} 0092-8674(02) 00808-5$

118. Kim DH, Sarbassov DD, Ali SM, Latek RR, Guntur KV, Erdjument-Bromage $\mathrm{H}$, et al. GbetaL, a Positive Regulator of the Rapamycin-Sensitive Pathway Required for the Nutrient-Sensitive Interaction Between Raptor and mTOR. Mol Cell (2003) 11(4):895-904. doi: 10.1016/s1097-2765(03)00114-x

119. Laplante M, Sabatini DM. mTOR Signaling in Growth Control and Disease. Cell (2012) 149(2):274-93. doi: 10.1016/j.cell.2012.03.017

120. Chen X, Liu M, Tian Y, Li J, Qi Y, Zhao D, et al. Cryo-EM Structure of Human mTOR Complex 2. Cell Res (2018) 28(5):518-28. doi: 10.1038/ s41422-018-0029-3
121. Zeng H, Yang K, Cloer C, Neale G, Vogel P, Chi H. Mtorcl Couples Immune Signals and Metabolic Programming to Establish T(reg)-Cell Function. Nature (2013) 499(7459):485-90. doi: 10.1038/nature12297

122. Schmitz F, Heit A, Dreher S, Eisenächer K, Mages J, Haas T, et al. Mammalian Target of Rapamycin (mTOR) Orchestrates the Defense Program of Innate Immune Cells. Eur J Immunol (2008) 38(11):2981-92. doi: $10.1002 /$ eji.200838761

123. Luo H, Duguid W, Chen H, Maheu M, Wu J. The Effect of Rapamycin on T Cell Development in Mice. Eur J Immunol (1994) 24(3):692-701. doi: 10.1002/eji.1830240331

124. Delgoffe GM, Pollizzi KN, Waickman AT, Heikamp E, Meyers DJ, Horton MR, et al. The Kinase mTOR Regulates the Differentiation of Helper T Cells Through the Selective Activation of Signaling by Mtorc1 and Mtorc2. Nat Immunol (2011) 12(4):295-303. doi: 10.1038/ni.2005

125. Lee K, Gudapati P, Dragovic S, Spencer C, Joyce S, Killeen N, et al. Mammalian Target of Rapamycin Protein Complex 2 Regulates Differentiation of Th1 and Th2 Cell Subsets via Distinct Signaling Pathways. Immunity (2010) 32(6):743-53. doi: 10.1016/j.immuni.2010.06.002

126. Chornoguz O, Hagan RS, Haile A, Arwood ML, Gamper CJ, Banerjee A, et al. Mtorc1 Promotes T-Bet Phosphorylation To Regulate Th1 Differentiation. J Immunol (Baltimore Md 1950) (2017) 198(10):3939-48. doi: 10.4049/ jimmunol.1601078

127. Oh WJ, Jacinto E. mTOR Complex 2 Signaling and Functions. Cell Cycle (Georgetown Tex) (2011) 10(14):2305-16. doi: 10.4161/cc.10.14.16586

128. Kurebayashi Y, Nagai S, Ikejiri A, Ohtani M, Ichiyama K, Baba Y, et al. PI3KAkt-Mtorc1-S6K1/2 Axis Controls Th17 Differentiation by Regulating Gfil Expression and Nuclear Translocation of Ror $\gamma$. Cell Rep (2021) 34 (12):108886. doi: 10.1016/j.celrep.2021.108886

129. Kim JS, Sklarz T, Banks LB, Gohil M, Waickman AT, Skuli N, et al. Natural and Inducible TH17 Cells are Regulated Differently by Akt and mTOR Pathways. Nat Immunol (2013) 14(6):611-8. doi: 10.1038/ni.2607

130. Cai Y, Xue F, Qin H, Chen X, Liu N, Fleming C, et al. Differential Roles of the mTOR-STAT3 Signaling in Dermal $\gamma \delta$ T Cell Effector Function in Skin Inflammation. Cell Rep (2019) 27(10):3034-48.e5. doi: 10.1016/j.celrep. 2019.05.019

131. Ren W, Yin J, Duan J, Liu G, Tan B, Yang G, et al. Mtorcl Signaling and IL17 Expression: Defining Pathways and Possible Therapeutic Targets. Eur J Immunol (2016) 46(2):291-9. doi: 10.1002/eji.201545886

132. Zhan CS, Chen J, Chen J, Zhang LG, Liu Y, Du HX, et al. CaMK4-Dependent Phosphorylation of Akt/mTOR Underlies Th17 Excessive Activation in Experimental Autoimmune Prostatitis. FASEB J Off Publ Fed Am Soc Exp Biol (2020) 34(10):14006-23. doi: 10.1096/fj.201902910RRR

133. Weichhart T, Säemann MD. T Helper Cell Differentiation: Understanding the Needs of Hierarchy. Immunity (2010) 32(6):727-9. doi: 10.1016/ j.immuni.2010.06.008

134. Chapman NM, Chi H. mTOR Signaling, Tregs and Immune Modulation. Immunotherapy (2014) 6(12):1295-311. doi: 10.2217/imt.14.84

135. Nagai S, Kurebayashi Y, Koyasu S. Role of PI3K/Akt and mTOR Complexes in Th17 Cell Differentiation. Ann New York Acad Sci (2013) 1280:30-4. doi: $10.1111 /$ nyas. 12059

136. Xia Y, Sun M, Xie Y, Shu R. mTOR Inhibition Rejuvenates the Aging Gingival Fibroblasts Through Alleviating Oxidative Stress. Oxid Med Cell Longev (2017) 2017:6292630. doi: 10.1155/2017/6292630

137. An JY, Quarles EK, Mekvanich S, Kang A, Liu A, Santos D, et al. Rapamycin Treatment Attenuates Age-Associated Periodontitis in Mice. GeroScience (2017) 39(4):457-63. doi: 10.1007/s11357-017-9994-6

138. Reynolds MA. Modifiable Risk Factors in Periodontitis: At the Intersection of Aging and Disease. Periodontol 2000 (2014) 64(1):7-19. doi: 10.1111/ prd. 12047

139. Hajishengallis G. Aging and its Impact on Innate Immunity and Inflammation: Implications for Periodontitis. J Oral Biosci (2014) 56 (1):30-7. doi: 10.1016/j.job.2013.09.001

140. Qin W, Huang QT, Weir MD, Song Z, Fouad AF, Lin ZM, et al. Alcohol Inhibits Odontogenic Differentiation of Human Dental Pulp Cells by Activating mTOR Signaling. Stem Cells Int (2017) 2017:8717454. doi: 10.1155/2017/8717454

141. Moschetta M, Reale A, Marasco C, Vacca A, Carratù MR. Therapeutic Targeting of the mTOR-Signalling Pathway in Cancer: Benefits and Limitations. Br J Pharmacol (2014) 171(16):3801-13. doi: 10.1111/bph.12749 
142. Ballou LM, Lin RZ. Rapamycin and mTOR Kinase Inhibitors. J Chem Biol (2008) 1(1-4):27-36. doi: 10.1007/s12154-008-0003-5

143. Linke M, Fritsch SD, Sukhbaatar N, Hengstschläger M, Weichhart T. Mtorc1 and Mtorc2 as Regulators of Cell Metabolism in Immunity. FEBS Lett (2017) 591(19):3089-103. doi: 10.1002/1873-3468.12711

144. Pattingre S, Espert L, Biard-Piechaczyk M, Codogno P. Regulation of Macroautophagy by mTOR and Beclin 1 Complexes. Biochimie (2008) 90 (2):313-23. doi: 10.1016/j.biochi.2007.08.014

145. Salmond RJ. mTOR Regulation of Glycolytic Metabolism in T Cells. Front Cell Dev Biol (2018) 6:122. doi: 10.3389/fcell.2018.00122

146. Pollizzi KN, Sun IH, Patel CH, Lo YC, Oh MH, Waickman AT, et al. Asymmetric Inheritance of Mtorcl Kinase Activity During Division Dictates CD8(+) T Cell Differentiation. Nat Immunol (2016) 17(6):704-11. doi: 10.1038/ni.3438

147. Cardoso EM, Arosa FA. CD8(+) T Cells in Chronic Periodontitis: Roles and Rules. Front Immunol (2017) 8:145. doi: 10.3389/fimmu.2017.00145

148. Rabinowitz JD, White E. Autophagy and Metabolism. Sci (New York NY) (2010) 330(6009):1344-8. doi: 10.1126/science.1193497

149. Ganley IG, Lam du H, Wang J, Ding X, Chen S, Jiang X. ULK1.ATG13.FIP200 Complex Mediates mTOR Signaling and is Essential for Autophagy. J Biol Chem (2009) 284(18):12297-305. doi: 10.1074/jbc.M900573200

150. Pua HH, Guo J, Komatsu M, He YW. Autophagy is Essential for Mitochondrial Clearance in Mature T Lymphocytes. J Immunol (Baltimore Md 1950) (2009) 182(7):4046-55. doi: 10.4049/jimmunol.0801143

151. Jia W, He YW. Temporal Regulation of Intracellular Organelle Homeostasis in T Lymphocytes by Autophagy. J Immunol (Baltimore Md 1950) (2011) 186 (9):5313-22. doi: 10.4049/jimmunol.1002404

152. Li C, Capan E, Zhao Y, Zhao J, Stolz D, Watkins SC, et al. Autophagy is Induced in CD4+ T Cells and Important for the Growth Factor-Withdrawal Cell Death. I Immunol (Baltimore Md 1950) (2006) 177(8):5163-8. doi: 10.4049/jimmunol.177.8.5163

153. Kim JJ, Lee HM, Shin DM, Kim W, Yuk JM, Jin HS, et al. Host Cell Autophagy Activated by Antibiotics Is Required for Their Effective Antimycobacterial Drug Action. Cell Host Microbe (2012) 11(5):457-68. doi: 10.1016/j.chom.2012.03.008

154. Bélanger M, Rodrigues PH, Dunn WA Jr, Progulske-Fox A. Autophagy: A Highway for Porphyromonas Gingivalis in Endothelial Cells. Autophagy (2006) 2(3):165-70. doi: 10.4161/auto.2828
155. Harris J, Hartman M, Roche C, Zeng SG, O'Shea A, Sharp FA, et al. Autophagy Controls IL-1beta Secretion by Targeting Pro-IL-1beta for Degradation. J Biol Chem (2011) 286(11):9587-97. doi: 10.1074/ jbc.M110.202911

156. Nakahira K, Haspel JA, Rathinam VA, Lee SJ, Dolinay T, Lam HC, et al. Autophagy Proteins Regulate Innate Immune Responses by Inhibiting the Release of Mitochondrial DNA Mediated by the NALP3 Inflammasome. Nat Immunol (2011) 12(3):222-30. doi: 10.1038/ni.1980

157. Zhou R, Yazdi AS, Menu P, Tschopp J. A Role for Mitochondria in NLRP3 Inflammasome Activation. Nature (2011) 469(7329):221-5. doi: 10.1038/ nature 09663

158. Bullon P, Cordero MD, Quiles JL, Ramirez-Tortosa Mdel C, GonzalezAlonso A, Alfonsi S, et al. Autophagy in Periodontitis Patients and Gingival Fibroblasts: Unraveling the Link Between Chronic Diseases and Inflammation. BMC Med (2012) 10:122. doi: 10.1186/1741-701510-122

159. Gu Y, Han X. Toll-Like Receptor Signaling and Immune Regulatory Lymphocytes in Periodontal Disease. Int J Mol Sci (2020) 21(9). doi: $10.3390 /$ ijms 21093329

Conflict of Interest: The authors declare that the research was conducted in the absence of any commercial or financial relationships that could be construed as a potential conflict of interest.

Publisher's Note: All claims expressed in this article are solely those of the authors and do not necessarily represent those of their affiliated organizations, or those of the publisher, the editors and the reviewers. Any product that may be evaluated in this article, or claim that may be made by its manufacturer, is not guaranteed or endorsed by the publisher.

Copyright (c) 2022 Jiang, Huang, Yu, Huang, Zhao and Chen. This is an open-access article distributed under the terms of the Creative Commons Attribution License (CC BY). The use, distribution or reproduction in other forums is permitted, provided the original author(s) and the copyright owner(s) are credited and that the original publication in this journal is cited, in accordance with accepted academic practice. No use, distribution or reproduction is permitted which does not comply with these terms. 